\section{Crop Production, Growth, and Ultimate Size of Cactus Pear Fruit following Fruit Thinning}

\author{
P. Inglese \\ Istituto di Colture Legnose Agrarie e Forestali Università di Reggio Calabria, \\ 89061 Reggio Calabria, Italy
}

\author{
G. Barbera, T. La Mantia, and S. Portolano \\ Istituto di Coltivazioni Arboree, Università di Palermo, 90128 Palermo, Italy
}

Additional index words. Opuntia ficus-indica, fruit quality

\begin{abstract}
We established a cladode load and thinning time that maximized fruit and flesh size in 'Gialla' cactus pear (Opuntia ficus-indica Mill.). Five weeks after spring flush removal, second flush flower buds were thinned to nine, six, or three per cladode; the same treatment was repeated during the early stages of fruit development. Control cladodes had a natural load of 15 fruit. Time of thinning did not affect fruit growth and ultimate weight. Fruit and flesh weight increased with thinning, but export weight was obtained only in cladodes with no more than six fruit. Heavier thinning did not result in any further increase of fruit or flesh weight. Percent flesh was not affected by thinning. Fruit characteristics, such as total soluble solids concentration and seed content did not change with thinning, but the seeds : flesh ratio decreased with thinning. Fruit on cladodes with the lowest load ripened earlier than those on more heavily yielding cladodes.
\end{abstract}

Crop load regulation by thinning serves to increase fruit size, advance fruit ripening (Barone et al., 1994; Havis, 1962), and control alternate bearing in fruit trees (Monselise and Goldschmidt, 1982). The extent of thinning is usually regulated on a fruit : leaf ratio and a tree age basis, but the time at which it is accomplished depends on fruit growth pattern, the length of the fruit development period (FDP), and prevailing environmental conditions (Byers, 1989; Faust, 1989). Fruit size in cactus pear depends on cultivar (Pimienta Barrios and Leguizamo, 1989), seed content (Barbera et al., 1994), water availability (Barbera, 1984), ripening time (Barbera et al., 1992), and cladode fruit load (Brutsch, 1992; Wessels, 1988). The cactus pear growth pattern also implies the growth of the flower buds because flowers average $25 \%$ to $30 \%$ of harvested fruit weight and $50 \%$ to $60 \%$ of their size (Barbera et al., 1992). Moreover, the high (90\% to $100 \%$ ) fruit set makes it possible to regulate crop load even before bloom with no need for further crop load adjustment. Cladode fertility differs greatly according to age (Inglese et al., 1994a) and developmental stage (Garcia de Cortazar and Nobel, 1992). Fully sun-exposed, 1-year-old cladodes might bear 20 to 25 fruit, but cladodes with nine to 15 fruit are the most common (Barbera and Inglese, 1993). Because, to our knowledge, only a limited amount of research has been devoted

Received for publication 15 Sept. 1993 Accepted for publication 9 Nov. 1994. The cost of publishing this paper was defrayed in part by the payment of page charges. Under postal regulations, this paper therefore must be hereby marked advertisement solely to indicate this fact.
Belice, Italy (lat. $37^{\circ} 44^{\top} \mathrm{N}$ ), on 10 -year-old, globe-shaped trees spaced $6 \times 4 \mathrm{~m}$ apart and furrow-irrigated once $(30 \mathrm{~mm}) 3$ weeks after full bloom.

Two thinning times (prebloom and postbloom) and four fruit loads (3, 6, 9, and 15 fruit/cladode) were compared in a complete randomized block design. The spring flush of flowers and cladodes was removed at full bloom (6 June 1992), and second budding started 2 weeks later. Five weeks after spring flush removal ( 2 weeks before second bloom), 105 cladodes with a natural load of 15 flower buds each were selected on five trees and thinned to nine, six, and three flower buds. The same extent of thinning was applied 1 week after bloom. Treatments were replicated on 15 single cladodes. Fifteen control cladodes were left with the initial load of 15 fruit. To avoid any effect of plant crop load on the singlecladode replications, all the fruiting cladodes not involved in the experiment were thinned to five flower buds 10 days before bloom; $95 \pm 5$ fruiting cladodes were left on each tree. Length, width, and fresh and dry weights of thinned flower buds and fruit were measured. Length and width were measured in the remaining

Table 1. Length, width, and fresh and dry weight of Opuntia ficus-indica 'Gialla' flower buds and fruit removed with thinning.

to fruit development and quality in relation to cladode load, we investigated the effect of timing and extent of thinning on growth and harvest quality of 'Gialla' cactus pear fruit.

\section{Material and Methods}

The experiment was performed in a commercial orchard located at Santa Margherita

\begin{tabular}{lcccc}
\hline Thinned & $\begin{array}{c}\text { Length } \\
(\mathrm{mm})\end{array}$ & $\begin{array}{c}\text { Width } \\
(\mathrm{mm})\end{array}$ & $\begin{array}{c}\text { Fresh } \\
\text { wt } \\
(\mathrm{g})\end{array}$ & $\begin{array}{c}\text { Dry } \\
\text { wt } \\
(\mathrm{g})\end{array}$ \\
\hline Flower buds & 51.63 & 28.80 & 21.60 & 1.61 \\
Fruit & 61.76 & 32.66 & 32.81 & 2.45 \\
& $* * *$ & $* * *$ & $* * *$ & $* *$
\end{tabular}

${ }^{* * *}$ Significant at $P=0.001$ according to Tukey's HSD test.

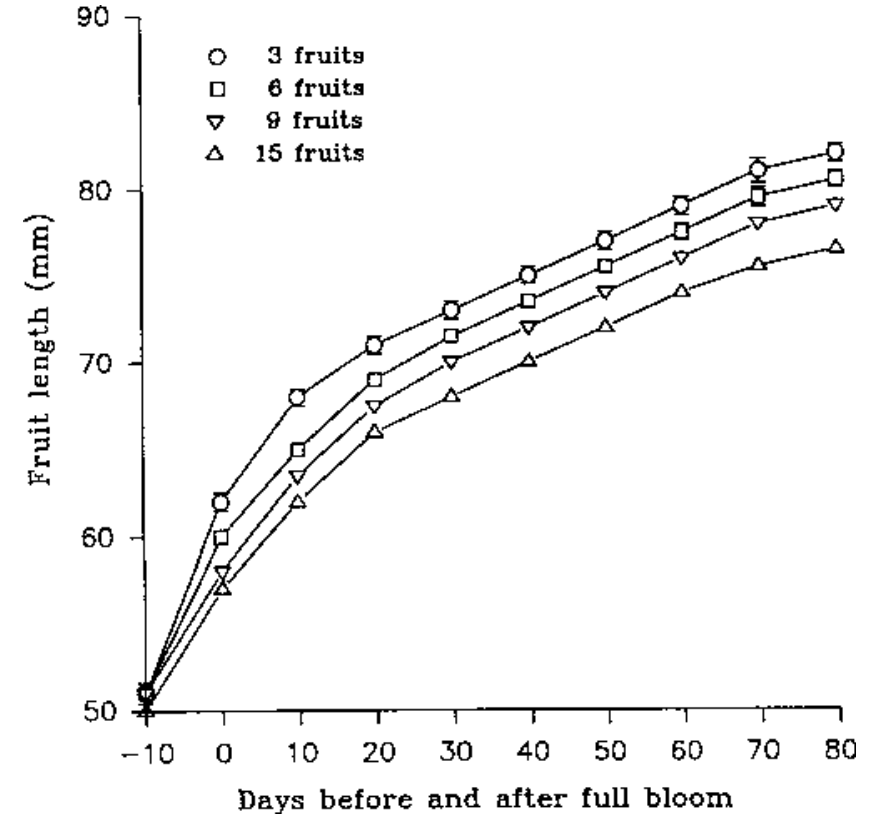

Fig. 1. Growth in length of Opuntia ficus-indica ('Gialla') fruit on cladodes with $15(\Delta)$ fruit or thinned to nine $(\nabla)$, six $(\square)$, and three $(\bigcirc) 10$ days before bloom. Bars are SE $(n=45)$ and are visible when larger than symbol. 


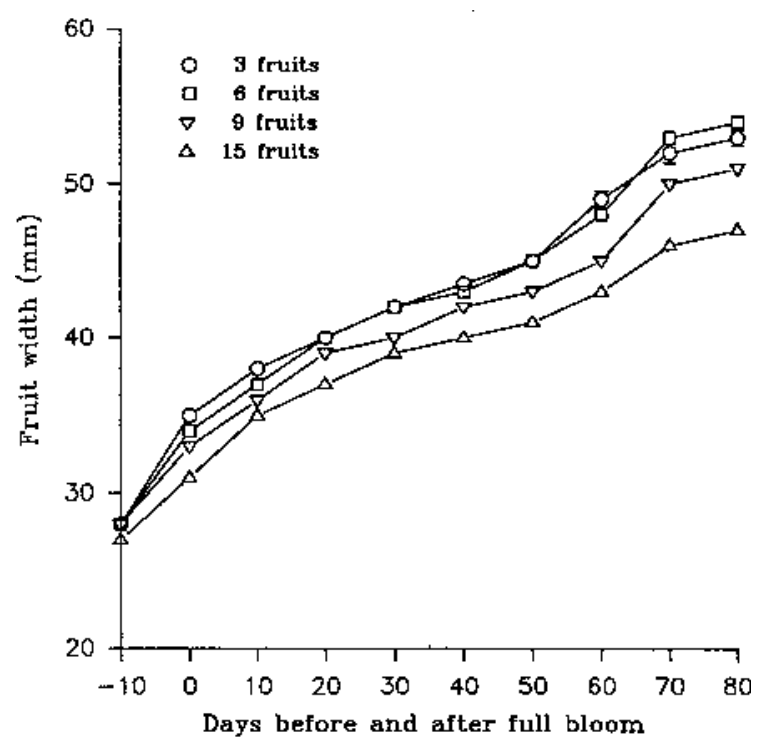

Fig. 2. Growth in width of Opuntia ficus-indica 'Gialla' fruit on cladodes with $(\Delta) 15$ fruit or thinned to $(\nabla)$ nine, $(\neg)$ six, and $(\bigcirc)$ three fruit 10 days before bloom. Bars are SE $(\mathrm{n}=45)$ and are visible when larger than symbol.

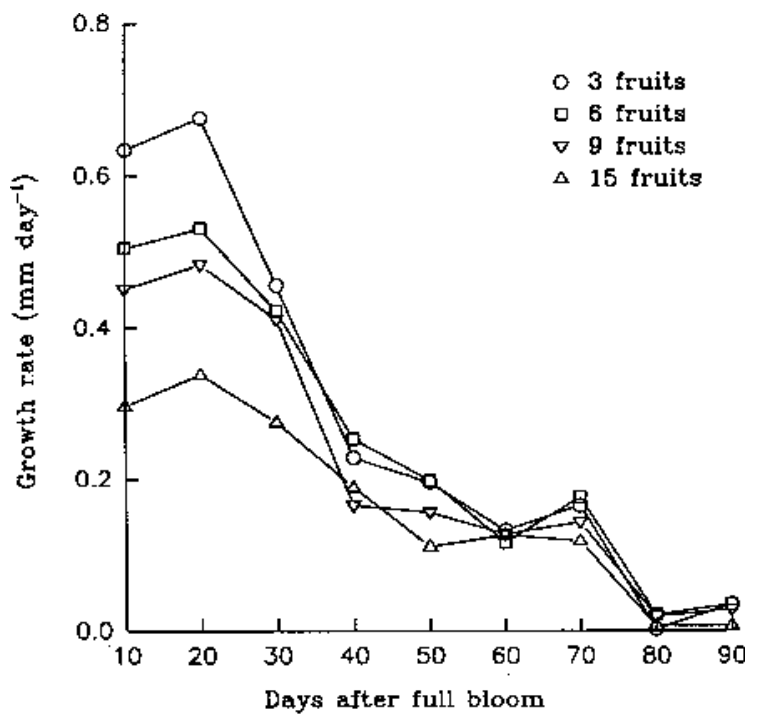

Fig. 3. Absolute width growth rate of Opuntia ficus-indica 'Gialla' fruit in cladodes with $(\Delta) 15$ fruit or thinned to $(\nabla)$ nine, $(\square)$ six, and $(\bigcirc)$ three fruit 10 days before bloom.

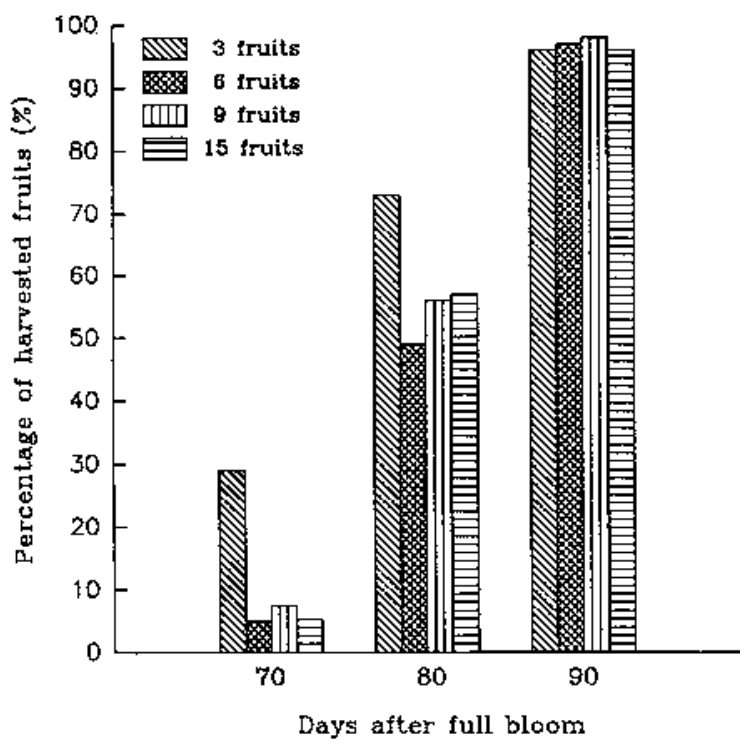

Fig. 4. Cumulative ripening pattern of Opuntia ficus-indica 'Gialla' fruit in cladodes with $(\Delta) 15$ fruit or thinned to $(\nabla)$ nine, $(\square)$ six, and $(\bigcirc)$ three fruit. fruit ( $n=45$ per treatment) at 10-day intervals from thinning time to harvest. Fruit were picked at commercial harvest maturity, when the peel color breaks from green to yellow. Fruit and flesh fresh weight were measured, and percent flesh was calculated. Dry weight ( $\mathrm{dw}$ ) was calculated according to the following equation: $\mathrm{dw}=-2.04+0.12 \mathrm{fw}\left(r^{2}=0.94\right)$, where $\mathrm{fw}$ is fruit fresh weight. Fresh and dry weights (70C to constant weight) were determined for 50 randomly selected fruit harvested at the same developmental stage. Total soluble solids concentration (TSSC) was measured with a digital refractometer (model Pr-1; ATAGO, Tokyo), and seeds were counted with an image analyzer (Barbera et al., 1994). Data were processed by a two-way analysis of variance and regression analyses.

\section{Results}

Differences between thinned flower buds and fruit were significant in terms of length, width, and fresh and dry weights (Table 1). Flower buds averaged $80 \%$ of fruit width, $88 \%$ of fruit length, and $65 \%$ of fresh and dry fruit weight. At thinning time, flower bud and fruit represented $20 \%$ to $13 \%$ and $30 \%$ to $22 \%$ of fresh and dry harvest fruit weight, respectively. Fruit growth rate was not affected by thinning (data not shown). Between treatments, differences in fruit length were significant throughout the FDP (Fig. 1), appeared soon after thinning, and remained constant until harvest. Differences in fruit width were significant throughout the FDP for cladodes with three or six fruit compared to those with nine or 15 (unthinned) fruit (Fig. 2 ). The latter fruit always were the shortest and narrowest. The fruit growth rate decreased with time. Differences in growth rate relative to the thinning treatments were evident during the first 40 to 50 days after bloom and decreased during subsequent fruit development (Fig. 3). Fruit were harvested from 70 to 90 days after bloom, but ripening time advanced only with three fruit per cladode (Fig. 4). Essentially all fruit were harvested by 90 days.

Fruit fresh and dry weight at harvest increased with the extent of thinning (Table 2), but time of thinning had no significant effect on fruit characteristics (data not shown). Fruit and flesh fresh weight increased by $35 \%$ when cladode load was reduced from 15 to six fruit; dry weight increased by $40 \%$. Heavier thinning did not result in any further significant increase of fruit weight (Table 2), but cladode yield was strongly depressed because the higher fruit weight did not make up for the lower number of fruit (Fig. 5). Despite the large difference in weight, percent flesh was not affected by thinning (Table 2). Only a few fruit reached export size $(\geq 120 \mathrm{~g})$ in the control (15 fruit) and partially thinned cladodes (nine fruit), but cladodes with the lowest load had the fewest undersized fruit (Fig. 6). Thinning did not result in any difference in TSSC or seed count; however, the seed content : flesh weight ratio decreased with thinning (Table 2). 
Table 2. Harvest characteristics of Opuntia ficus-indica 'Gialla' fruit in relation to the extent of thinning. Fruit retained $\times$ time of thinning interaction was nonsignificant.

\begin{tabular}{|c|c|c|c|c|c|c|c|}
\hline \multirow{2}{*}{$\begin{array}{l}\text { Fruit } \\
\text { retained }\end{array}$} & \multicolumn{2}{|c|}{ Fresh wt (g) } & \multirow{2}{*}{$\begin{array}{c}\text { Flesh } \\
(\%)\end{array}$} & \multirow{2}{*}{$\begin{array}{c}\text { Fruit } \\
\text { dry wt } \\
(\mathrm{g})\end{array}$} & \multirow{2}{*}{$\begin{array}{c}\mathrm{TSSC}^{\mathrm{z}} \\
(\%)\end{array}$} & \multirow{2}{*}{$\begin{array}{c}\text { Seed } \\
\text { count } \\
\text { (no.) }\end{array}$} & \multirow{2}{*}{$\begin{array}{r}\text { Seed/ } \\
\text { g flesh } \\
(\text { no. })\end{array}$} \\
\hline & Fruit & Flesh & & & & & \\
\hline 3 & 129 & 80.0 & 61.8 & 12.6 & 13.6 & 280 & 3.5 \\
\hline 6 & 126 & 78.6 & 62.3 & 12.3 & 13.3 & 274 & 3.5 \\
\hline 9 & 99.5 & 61.0 & 61.3 & 9.4 & 13.5 & 246 & 4.0 \\
\hline 15 & 92.3 & 56.4 & 61.1 & 8.7 & 13.5 & 256 & 4.5 \\
\hline \multicolumn{8}{|l|}{ Coefficient } \\
\hline Linear & $* * *$ & $* * *$ & NS & $* * *$ & NS & NS & $* * *$ \\
\hline Quadratic & NS & NS & NS & NS & NS & NS & NS \\
\hline Deviation & $* * *$ & $* * *$ & NS & $* * *$ & NS & NS & NS \\
\hline
\end{tabular}

${ }^{2} \mathrm{TSSC}=$ total soluble solids concentration.

${ }_{\text {ss, }, * *}$ Nonsignificant or significant at $P=0.001$, respectively.

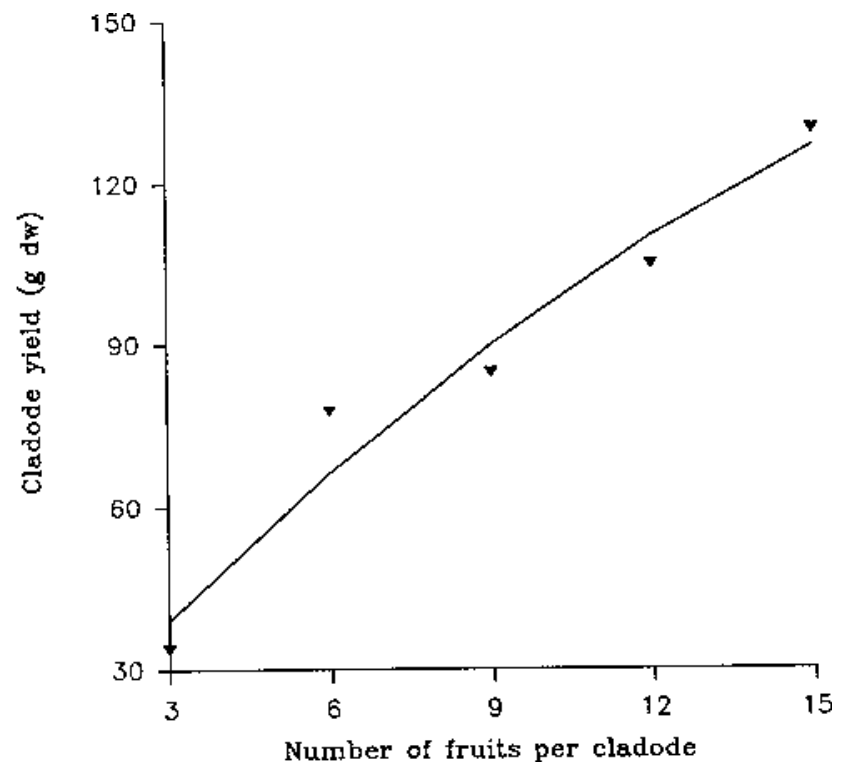

Fig. 5. Relationship between number of fruit per cladode and cladode yield (on dry weight basis). Each point is the mean of 15 single-cladode replications $\left(y=8.2-0.198 b+10.87 \mathrm{c} ; r^{2}=0.96\right)$.

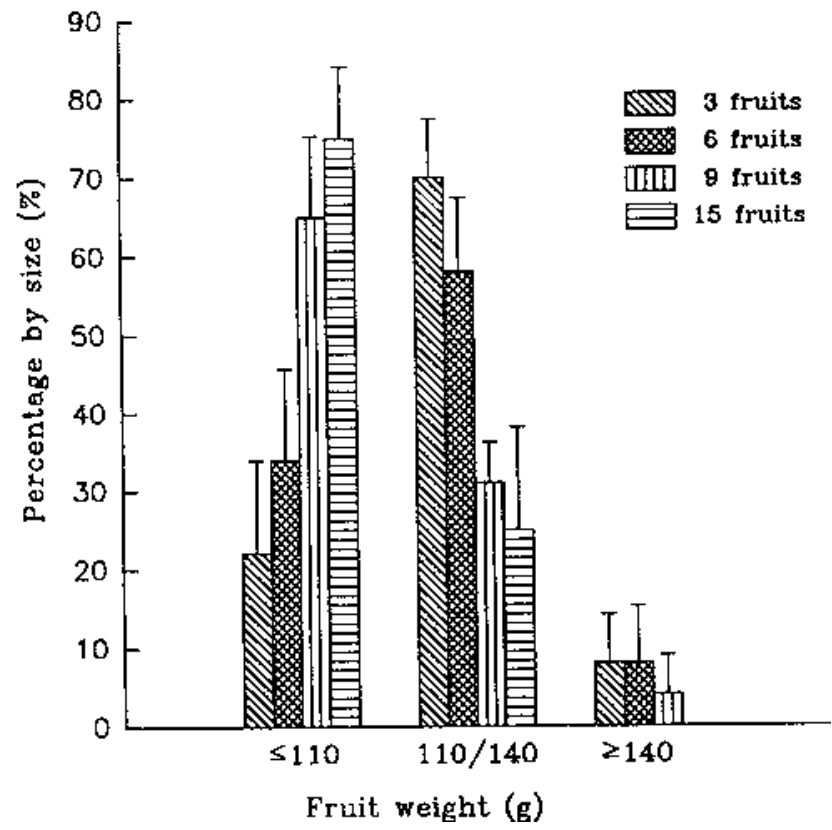

Fig. 6. Distribution of Opuntia ficus-indica 'Gialla' fruit by size in cladodes with 15, 9, 6, and 3 fruit. Bars are SE $(\mathrm{N}=45)$.

\section{Discussion}

Fruit growth potential of cactus pears depends on seed content (Barbera et al., 1994). Actual fruit weight is affected by competition at the cladode level, and fruit with the same seed count vary greatly in the weight and seed : flesh ratio, according to the number of fruit per cladode.

Our results indicate that optimal fruit weight and quality can be attained with six fruit per fruiting cladode. A lower fruit load does not result in any further increase of fruit weight, but it strongly reduces yields. In fact, Inglese et al. (1994b) recently demonstrated that a fruiting cladode supports the growth of five fruit throughout the FDP, but extensive assimilate import from neighboring cladodes occurs with more than five fruit per cladode, particularly during the last 4 weeks of FDP.

Thinning could be performed for a long period (from budbreak to the early stages of fruit development). However, the asynchronous budbreak and flower bud development suggests thinning 10 to 20 days after bloom, when differences in fruit size are clear enough and flesh development is still negligible (Barbera et al., 1992). Cladode size (surface area and thickness) and fruit load per cladode and plant level also should be considered to determine optimal thinning ratios. Considering a plant spacing of $6 \times 4 \mathrm{~m}$ and an average of 50 to 70 fruiting cladodes per mature tree (Barbera and Inglese, 1993), a cladode load of six fruit will give 15 to $20 \mathrm{t}$ fruit/ha of (Fig. 7). Larger crops might be obtained by increasing either the number of 1-year-old fruiting cladodes per tree or plant density. However, such planting and management strategies need to be evaluated in relation to plant fruitfulness and orchard efficiency.

\section{Literature Cited}

Barbera, G. 1984. Ricerche sull'irrigazione del ficodindia. Frutticoltura 8:49-55.

Barbera, G., F. Carimi, P. Inglese, and M. Panno. 1992. Physical, morphological and chemical changes during fruit development and ripening in three cultivars of prickly pear, Opuntia ficusindica (L.) Miller. J. Hort. Sci. 67:307-312.

Barbera, G. and P. Inglese. 1993. La Coltura del Ficodindia. Calderini Edagricole, Bologna, Italy.

Barbera, G., P. Inglese, and T. La Mantia. 1994. Seed content and fruit characteristics in cactus pear (Opuntia ficus-indica Mill.). Scientia Hort. 58:161-165.

Barone, E., G. Gullo, R. Zappia, and P. Inglese. 1994. Effect of crop load on fruit ripening and olive oil (Olea europea L.) quality. J. Hort. Sci. 69:67-73.

Brutsch, M.O. 1992. Crop manipulation in spineless prickly pear (Opuntia ficus-indica) in South Africa. II Congreso Internacional de Tuna y Cochinilla, Santiago, Chile, 22-25 Sept. 1992.

Byers, R.E. 1989. Response of peac

$\mathrm{h}$ trees to bloom thinning. Acta Hort. 254:125-132.

Faust, M. 1989. Physiology of temperate zone fruit trees. Wiley, New York.

Garcia de Cortazar, V. and P.S. Nobel. 1992. Biomass and fruit production for the prickly pear cactus, Opuntiaficus-indica. J. Amer. Soc. Hort. Sci. 117:568-572.

Havis, A.L. 1962. Effect of time of fruit thinning of 


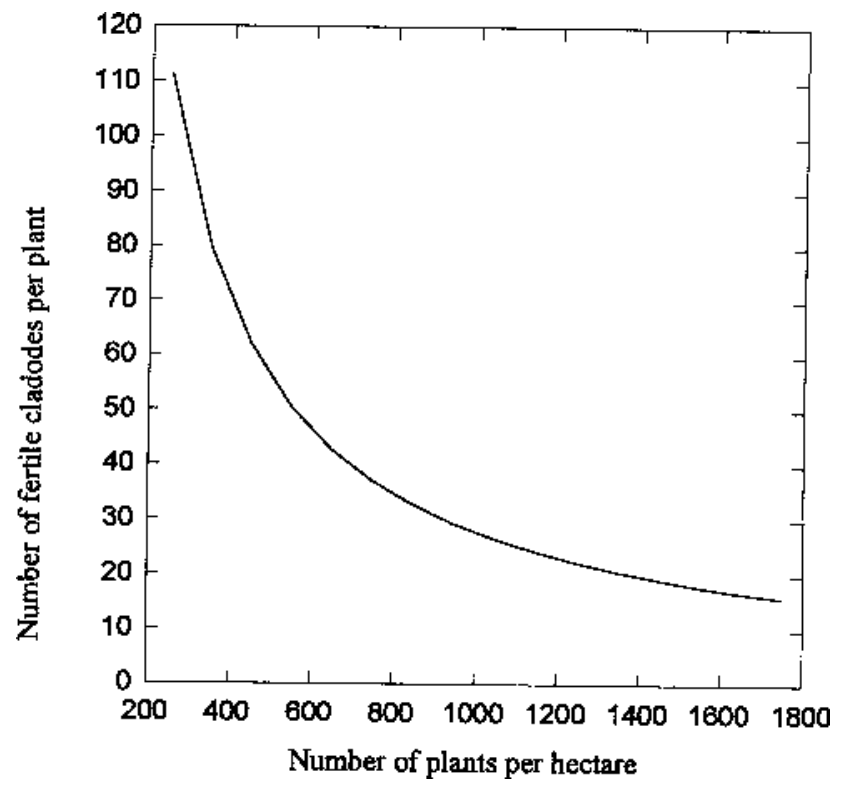

Redhaven peach. Proc. Amer. Soc. Hort. Sci. 80:172-176.

Inglese, P., G. Barbera, and F. Carimi. 1994a. The effect of different amounts of cladode removal on reflowering of cactus pear (Opuntia ficusindica (L.) Mill.). J. Hort. Sci. 69:61-65.

Inglese, P., A.A. Israel, and P.S. Nobel. 1994b. Growth and $\mathrm{CO}_{2}$ uptake for cladodes and fruit of the CAM species Opuntia ficus-indica during fruit development. Physiol. Plant. 91:708-714.

Monselise, S.P. and E.E. Goldschmidt. 1982. Alternate bearing in fruit trees. Hort. Rev. 4:128-174.

Pimienta Barrios, E. and R.M. Leguizamo. 1989. Variacion en componentes del fruto maduro entre formas de nopal (Opuntia spp.) tunero. Revista Fitotecnica Mexicana 12:183-196.

Wessels, A.B. 1988. Spineless prickly pear. Perskor Publishers, Johannesburg, South Africa.

Fig. 7. Number of fertile cladodes required for $20 \mathrm{t}$ fruit/ha production (average fresh weight $120 \mathrm{~g}$ ), with a cladode fertility of six fruit in relation to orchard density. 